\title{
Constraint-induced movement therapy of upper limb of children with cerebral palsy in clinical practice: systematic review of the literature
}

\author{
Terapia de movimento induzido por restrição do membro superior de crianças com \\ paralisia cerebral na prática clínica: uma revisão sistemática da literatura
}

Terapia de movimiento inducido por restricción para el miembro superior de niños con parálisis cerebral en práctica clinica: revisión sistemática de la literatura

\begin{abstract}
Paulo Roberto Fonseca Junior', Eduardo Filoni',2, Chrystianne Melo Setter', Andréia Marques Berbel', Antônio Olival Fernandes ${ }^{3}$, Renata Calhes de Franco Moura ${ }^{1,4}$
\end{abstract}

\begin{abstract}
The purpose of the present study was to perform a systematic review of the literature to investigate how and with what modifications or adaptations constraintinduced movement therapy has been employed in clinical practice for therapeutic interventions in children with cerebral palsy. Searches were conducted of the CAPES (Brazilian fostering agency) periodical portal, Pubmed, Bireme, Science Direct, Scielo and PEDro databases for relevant articles published between January 2010 and May 2016. The articles retrieved were evaluated, scored and qualified by two blinded reviewers using the Physical therapy Evidence Database Scale. The searches led to the retrieval of 102 articles, 12 of which were included in the present systematic review. A table was created containing information on the study groups, inclusion criteria, intervention, intervention frequency, difficulties encountered, evaluations and outcomes. Considerable variety was found in the therapeutic intervention models. The findings of the present review demonstrate that constraint-induced movement therapy in pediatric clinical practice is not employed in its original form. Although the studies analyzed did not have a common methodology regarding the use of this type of therapy, the method has been adapted with considerable flexibility, providing promising, positive results regarding the therapeutic intervention of the paretic upper limb in children with cerebral palsy.
\end{abstract}

Keywords I Cerebral Palsy; Upper Extremity; Hemiplegia; Immobilization; Movement.
RESUMO | Este estudo se propôs a realizar uma revisão sistemática da literatura para investigar como e com que modificações ou adaptações a terapia de movimento induzido por restrição tem sido empregada na prática clínica para intervenções terapêuticas em crianças com paralisia cerebral. As pesquisas foram conduzidas do portal periódico da CAPES (Agência brasileira de amparo), e dos bancos de dados Pubmed, Bireme, Science Direct, Scielo e PEDro para artigos relevantes publicados entre janeiro de 2010 e maio de 2016. Os artigos obtidos foram avaliados, quantificados e qualificados por dois revisores anônimos usando a Base de Dados em Evidências em Fisioterapia. As pesquisas levaram para a recuperação de 102 artigos, 12 dos quais foram incluídos nesta revisão sistemática. Uma tabela foi criada contendo informações sobre os grupos de estudo, critérios de inclusão, intervenção, frequência de intervenção, dificuldades encontradas, avaliações e resultados. Foi encontrada uma variedade considerável nos modelos de intervenção terapêutica. Os resultados desta revisão demonstram que a terapia de movimento induzido por restrição na prática clínica pediátrica não é empregada na sua forma original. Embora os estudos analisados não tenham uma metodologia comum em relação ao uso deste tipo de terapia, o método foi adaptado com flexibilidade considerável, fornecendo resultados promissores e positivos sobre a intervenção terapêutica do parético membro superior em crianças com paralisia cerebral. Descritores I Paralisia Cerebral; Extremidade Superior; Hemiplegia; Imobilização; Movimento.

'Physical therapy Program at the Universidade de Mogi das Cruzes.

${ }^{2}$ Professor of the Physiotherapy Department of Universidade Cruzeiro do Sul.

${ }^{3}$ Physiotherapist of the Hospital and Maternity School Vila Nova Cachoeirinha.

${ }^{4}$ Graduate Program in Rehabilitation Sciences, Universidade de Nove de Julho. 
RESUMEN | El propósito del presente estudio fue realizar una revisión sistemática de la literatura para investigar cómo y con qué modificaciones o adaptaciones la terapia de movimiento inducido por restricción ha sido empleada en la práctica clínica para intervenciones terapéuticas en niños con parálisis cerebral. Se realizaron búsquedas en CAPES (Agencia brasileña de fomento) portal periodico, Pubmed, Bireme, Science Direct, Scielo y PEDro bases de datos para artículos relevantes publicados entre enero de 2010 y mayo de 2016. Los artículos recuperados fueron evaluados, puntuados y calificados por dos revisores ciegos utilizando la Escala de base de datos de Pruebas de Fisioterapia (Physical therapy Evidence Database Scale). Las búsquedas condujeron a la recuperación de 102 artículos, 12 de los cuales se incluyeron en la presente revisión sistemática. Se creó una tabla que contiene información sobre los grupos de estudio, criterios de inclusión, intervención, frecuencia de intervención, dificultades encontradas, evaluaciones y resultados. Se encontró una variedad considerable en los modelos de intervención terapéutica. Los resultados de la presente revisión muestran que la terapia de movimiento inducido por restricción en la práctica clínica pediátrica no se emplea en su forma original. Aunque los estudios analizados no tenían una metodología común respecto al uso de este tipo de terapia, el método se ha adaptado con una flexibilidad considerable, promoviendo resultados promisores y positivos con respecto a la intervención terapéutica del miembro parético superior en niños con parálisis cerebral.

Palabras clave I Parálisis Cerebral; Extremidad Superior; Hemiplejía; Inmovilización; Movimiento.

\section{INTRODUCTION}

Cerebral palsy $(\mathrm{CP})$ is a group of movement and postural development disorders that causes limitations with regard to activities of daily living due to a nonprogressive brain damage, occurring during fetal or infant development, resulting in chronic physical deficiencies and possible sensory deficits ${ }^{1}$. Motor impairment is the major characteristic of $\mathrm{CP}$ and is characterized by the type of motor disorder (spasticity, ataxia, dystonia and athetosis) as well as the predominance of the affected limbs (hemiparesis, paraparesis and tetraparesis) ${ }^{2}$.

Hemiparesis is the most frequent manifestation of $\mathrm{CP}$, affecting as many as $38 \%$ of cases in one populationbased study ${ }^{2}$, and can lead to disuse of the affected upper limb, with negative consequences for reaching, bimanual tasks and functionality, regarding activities performed in home, school and community settings ${ }^{3}$.

In recent years, a large number of randomized clinical trials, investigating particularly CIMT and "modified CIMT" (mCIMT) have emerged ${ }^{4}$. CIMT began with preclinical research involving young male primates and was founded on overcoming "learned non-use". Some researchers suggest two possible mechanisms that can lead to functional improvements of the paretic upper limb through CIMT: overcoming "learned non-use", which is the learning of a patient not to use the paretic limb due to the difficulty encountered; and cortical reorganization, involving anatomic connections through neuronal sprouting, the enhancement of synaptic efficiency of existing connections (disinhibition) or the recruitment of a large number of neurons in the innervation of the affected limb, adjacent to those involved before the brain damage $e^{6,7}$.

These strategies combine the principles of motor learning (practice, specificity feedback, etc.) and neuroplasticity (cerebral changes induced by the practice of repeated actions that enhance movement complexity, motivation and reward) in intensive blocks of training sessions ${ }^{8}$. The classic CIMT, described in previous studies ${ }^{9,10}$, was initially developed for adults with hemiparesis after stroke. This involves restriction of the upper limb not affected by $90 \%$ of the waking hours for at least 2 weeks, while the upper limb is intensively trained for 3 hours or more per day ${ }^{11}$. During this approach, the paretic limb is used for numerous activities involving two aspects: the practice of repetitive tasks and training. In the first, the tasks are carried out continuously for 15 to 20 minutes to practice the movement incorporated into a functional task. In this approach, movement is practiced first, followed by performance of the functional task. Environments can be manipulated to vary the requirements of the task and induce specific movements, or to change the degree of difficulty. Tasks are planned so that frequent successes can be achieved. Training involves a meta-motor task performed in small steps with increasing degrees of difficulty, based on the patient's abilities ${ }^{1}$.

Modifications to the classic protocol (mCIMT) were made to encourage children to perform. The mCIMT 
protocols similarly involve restraint of the non-affected limb with variations in the type of restriction applied (e.g., glove, glove, sling) and are accompanied by a unimanual repetitive practice, differing in part from the classic CIMT in terms of the model of therapy (short-term intensity, long-term distribution model) and dose intervention ${ }^{4}$. The location, context and provider of training (house/camp, individual/group, therapist/parent) are also differentiated in relation to the classic CIMT ${ }^{11}$. Recently, hybrid models have been reported applying sequentially mCIMT followed by bimanual training, significantly altering the unimanual construction of the method ${ }^{4,11}$.

CIMT is an analytical-behavioral technique designed to improve deficits resulting from different types of damage to the central nervous system, such as stroke, traumatic brain injury, spinal cord injury, multiple sclerosis, $\mathrm{CP}$ and other disorders. The deficits are mainly of a motor nature, but also include verbal aspects (aphasia) and phantom limb pain following an amputation $^{12}$.

The study by DeLuca et al. ${ }^{13}$ was the first to test the effectiveness of CIMT in children through a randomized controlled crossover study. The treatment protocol was originally developed and evaluated for a 15 -month-old child, with virtually no voluntary use of upper limbs and a contemptuous almost complete development by his compromised upper limb.

Learned non-use also occurs in individuals with hemiparetic $\mathrm{CP}$, who do not employ the affected arm for diverse tasks. Thus, CIMT is a therapeutic resource that enables the use of the paretic upper limb in unimanual tasks. However, a major concern in relation to the administration of CIMT to children with hemiparetic $\mathrm{CP}$ regards the impact on the child's self-esteem. Unlike stroke survivors, who are often very motivated to recover lost function, children with $\mathrm{CP}$ may have never used the paretic limb during functional activities and are therefore obligated to concentrate on their deficiencies. Moreover, the high rate of early failures during the execution of such tasks can be the cause of considerable frustration. Another point of concern with classic CIMT for pediatric patients is related to the use of the constraint during the rest of the $90 \%$ of the day, forcing children to continue exclusively using their compromised limb. This demand can be the source of additional frustration, resulting in concerns on the part of the family regarding the potential risk of falls due to the constraint of the unaffected limb. Thus, the procedures involved in CIMT for adults may not be altogether appropriate for children ${ }^{1}$.

Recent systematic reviews of literature and metaanalysis ${ }^{11,14,15}$ have addressed the effectiveness of the use of CIMT in children with CP, reporting results such as improvements in the manual capacity of the affected limb. The aim of the present study was to perform a systematic review of the literature to investigate how and with which modifications or adaptations CIMT has been used in the therapeutic process of children with hemiparetic $\mathrm{CP}$, without merit on the evaluation of the results obtained in the clinical trials

\section{METHODOLOGY}

Searches were conducted from the CAPES (Brazilian fostering agency) periodical portal, Pubmed, Bireme, Science Direct, Scielo and PEDro databases for relevant articles published between January 2010 and May 2016, using the following keywords in English, Spanish and Portuguese. The search for the articles was done using the terminology registered in the Descriptors in Health Sciences (DECS) and Medical Subject Headings of the U.S. National Library of Medicine (Mesh). They were: cerebral palsy, upper extremity, hemiplegia, immobilization, movement. All the synonyms of these descriptors were considered for the search.

The following were the inclusion criteria: 1) type of study - controlled clinical trial; 2) intervention constraint-induced movement therapy for the upper limb; 3) experimental group - children with cerebral palsy; 4) publication between 2010 and 2016; and 5) score of 5 or more points on the Physical therapy Evidence Database Scale (PEDro). Titles and abstracts were analyzed in the first stage of the selection process. Pre-selected articles were then submitted to fulltext analysis for the determination of inclusion to the systematic review based on the eligibility criteria.

Pre-selected articles were evaluated for methodological quality using the 11-item PEDro scale. All items (except Item 1, which is not scored) received a score of either 1 or 0 depending respectively on the presence or absence of the criterion in question. Thus, the final score ranges from 0 to 10 points. The purpose of this scale is to offer a numeric representation of the methodological quality of randomized and controlled clinical trials, placing emphasis on internal validity (whether the results 
provide sufficient information) as well as clinical and statistical relevance, in a way that the interpretation of the findings is clear and other researchers can reproduce the study. The classification of the analyzed studies based on the PEDro scale was performed by two evaluators, independently and blind to the objective of the present study, so that if a controversy occurred to the score obtained in the study, a third evaluator would be selected to answer the question of the score. The articles selected by inclusion criterion through the PEDro scale would have to have a score greater than or equal to 6 (table 2 ).

The PEDro scale was created based on the Delphi list of criteria for the quality evaluation of randomized clinical trials to be included in systematic reviews. This list was developed from the consensus of a panel of experts in 1998, but was considered insufficient regarding statistical parameters. The creation and validation of an adequate measure for the evaluation of methodological quality stemmed from the need to catalog clinical trials in the Physical therapy Evidence Database (PEDro). The purpose of the PEDro scale is to assist researchers in the rapid identification of which known or suspected (i.e., randomized controlled study or controlled clinical trial) randomized clinical trials indexed in the PEDro databank are internally valid (Items 2 to 9) and have sufficient statistical information for the adequate interpretation of the results (Items 10 and 11). An additional criterion (Item 1), which is related to external validity (generalizability or applicability of the trial), was maintained so that the content of the Delphi list would be complete, but this criterion is not used to calculate the methodological quality score. However, the PEDro scale should not be used as a validity measure of conclusion from a study or to compare the quality of clinical trials conducted in different fields of therapy, because it is not possible to meet all scale items in some areas of physical therapy. Moreover, studies with significant treatment effects and high PEDro scores do not necessarily provide evidence of a clinically useful treatment ${ }^{16}$.

All articles that met the inclusion criteria and received a score of 6 or more points on the PEDro scale were included in the present systematic review. Table 2 offers a summary of the studies and relevant characteristics. The "groups" column contains information on sample size. The inclusion criteria are listed to allow a comparison of patient characteristics and the results. Type and frequency of the intervention employed are essential for understanding how CIMT is performed in clinical practice. The "evaluation" column lists the measures employed in the different studies for the assessment of the findings reliability. Finally, the "difficulties encountered" column lists problems involved in managing CIMT to children, which is analyzed in depth in the study by Gordon et al. ${ }^{1}$. Table 3 lists the main outcomes of the clinical trials analyzed in the present systematic review.

\section{RESULTS}

One hundred two articles were retrieved from the initial searches of the databases. Following the analyses of the titles, abstracts and full texts as well as the scoring of methodological quality using the PEDro scale (score of 6 or more points), 12 articles met the eligibility criteria and were selected for the present systematic review. Figure 1 displays the flowchart of the article selection process. 


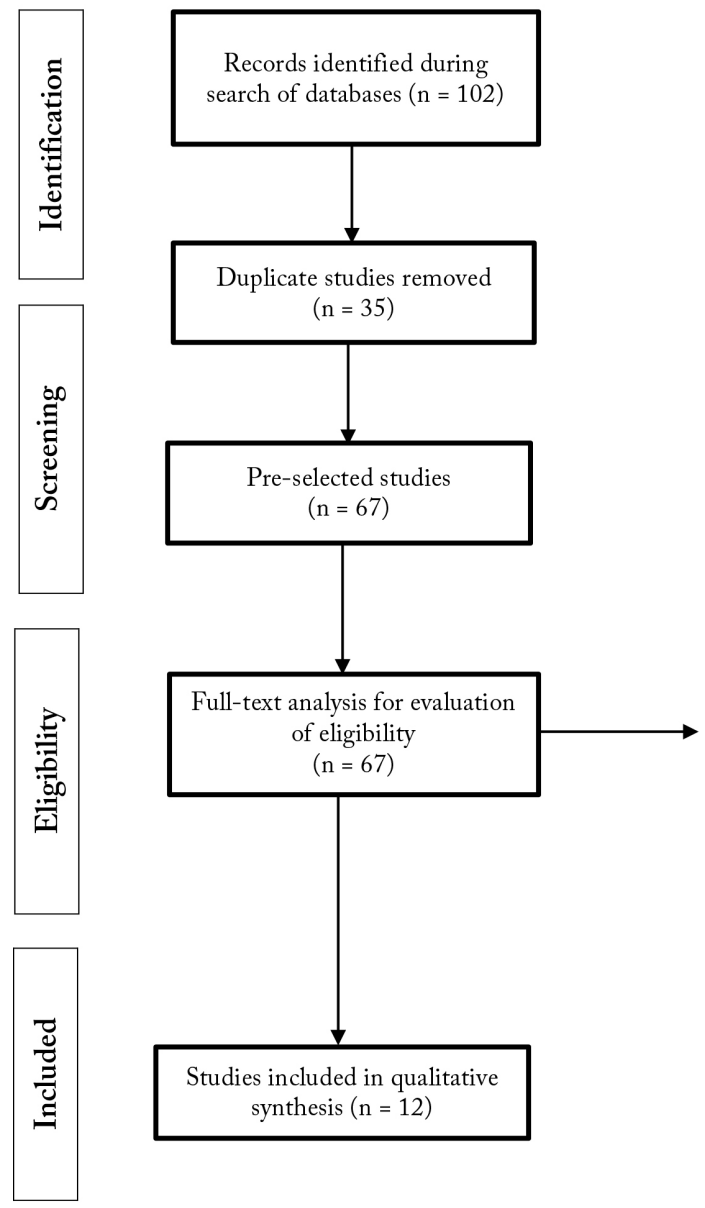

Articles excluded $(\mathrm{n}=55)$

Low score PEDro $=5$

Turkish language $=1$

No control group $=3$

Case report $=8$

Pilot study $=1$

Protocol study $=3$

Review study $=4$

Retrospective study $=1$

No full assessment on upper

$\operatorname{limb}=12$

Intervention/evaluation on

lower limbs alone $=1$

Other etiologies besides

cerebral palsy $=1$

Studies without objective to

evaluate intervention with

$\mathrm{CIMT}=15$

Figure 1 - Overview of selection process

Table 1 - Methodological quality score of each study (PEDro scale)

\begin{tabular}{|c|c|c|c|c|c|c|c|c|c|c|c|c|c|}
\hline \multirow{2}{*}{\multicolumn{2}{|c|}{ Reference }} & \multicolumn{11}{|c|}{ Item } & \multirow[b]{2}{*}{ ఫ్ర } \\
\hline & & $\begin{array}{l}\text { 를 } \\
\frac{0}{\overline{0}} \\
\text { 흔 }\end{array}$ &  & 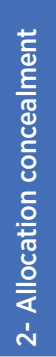 & 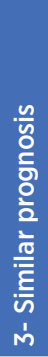 & 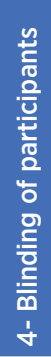 & 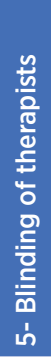 & 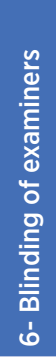 &  & 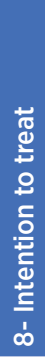 & 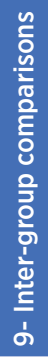 & 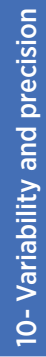 & \\
\hline 1 & Aarts PB. et al ${ }^{17}$ & 1 & 1 & 0 & 1 & 0 & 0 & 1 & 1 & 0 & 1 & 1 & $6 / 10$ \\
\hline 2 & Aarts PB. et al ${ }^{18}$ & 1 & 1 & 0 & 1 & 0 & 0 & 1 & 1 & 0 & 1 & 1 & $6 / 10$ \\
\hline 3 & Brandão MB. et al..$^{19}$ & 1 & 1 & 1 & 1 & 0 & 0 & 0 & 1 & 0 & 1 & 1 & $6 / 10$ \\
\hline 4 & tBrandão MB. et al. ${ }^{20}$ & 1 & 1 & 1 & 1 & 0 & 0 & 1 & 1 & 1 & 1 & 1 & $8 / 10$ \\
\hline 5 & Chen HC.et al. ${ }^{21}$ & 1 & 1 & 1 & 1 & 0 & 0 & 1 & 1 & 0 & 1 & 1 & $7 / 10$ \\
\hline 6 & Chen CL.et al. ${ }^{22}$ & 1 & 1 & 0 & 1 & 0 & 0 & 1 & 1 & 0 & 1 & 1 & $6 / 10$ \\
\hline 7 & Choudhary A. et al. ${ }^{23}$ & 1 & 1 & 1 & 1 & 0 & 0 & 1 & 1 & 1 & 1 & 1 & $8 / 10$ \\
\hline 8 & Hsin YJ. et al. ${ }^{24}$ & 1 & 1 & 1 & 1 & 0 & 0 & 1 & 1 & 0 & 1 & 1 & $7 / 10$ \\
\hline 9 & Sakzewski L et al. ${ }^{25}$ & 1 & 1 & 1 & 1 & 0 & 0 & 1 & 1 & 1 & 1 & 1 & $8 / 10$ \\
\hline 10 & Sakzewski L et al. ${ }^{26}$ & 1 & 1 & 1 & 1 & 0 & 0 & 1 & 0 & 0 & 1 & 1 & $6 / 10$ \\
\hline 11 & Case-Smith J. et al. ${ }^{27}$ & 1 & 1 & 0 & 1 & 0 & 0 & 1 & 1 & 0 & 1 & 1 & $6 / 10$ \\
\hline 12 & Wallen M. et al..28 & 1 & 1 & 0 & 1 & 0 & 0 & 1 & 1 & 1 & 1 & 1 & $7 / 10$ \\
\hline
\end{tabular}




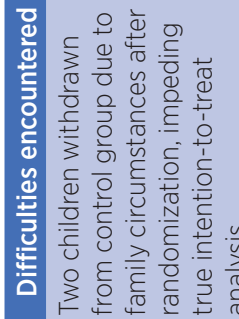

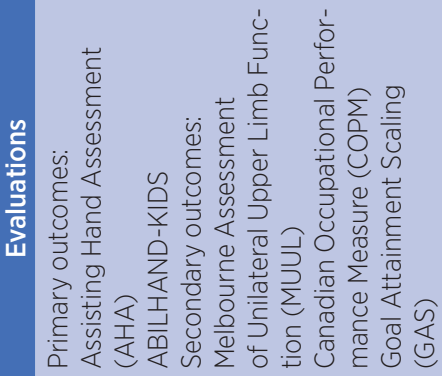

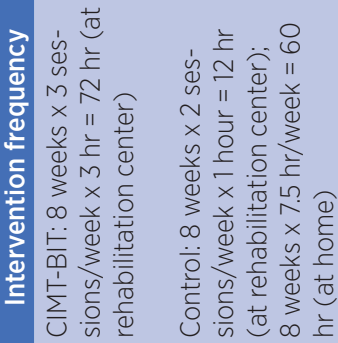

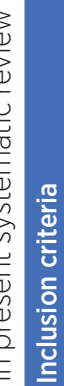

응

용

핟

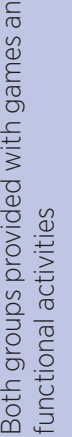

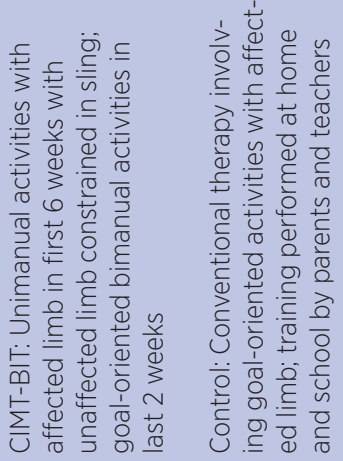

$\frac{1}{\frac{10}{0}}$

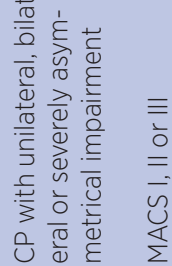

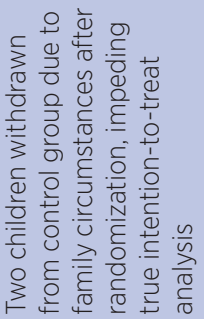

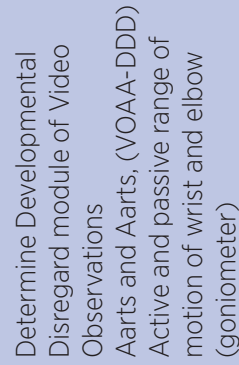


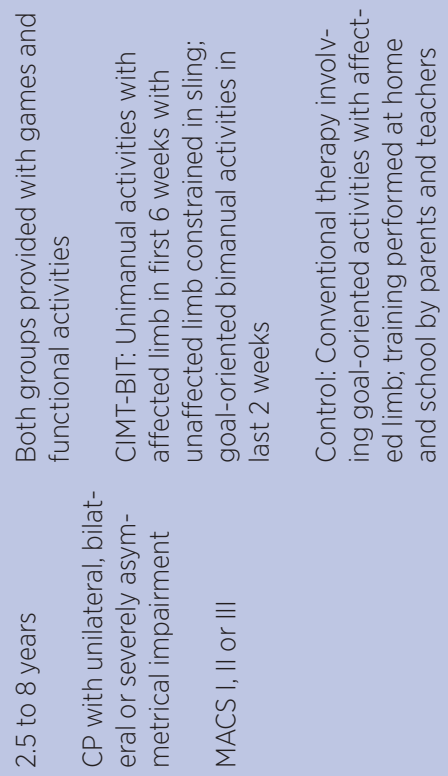


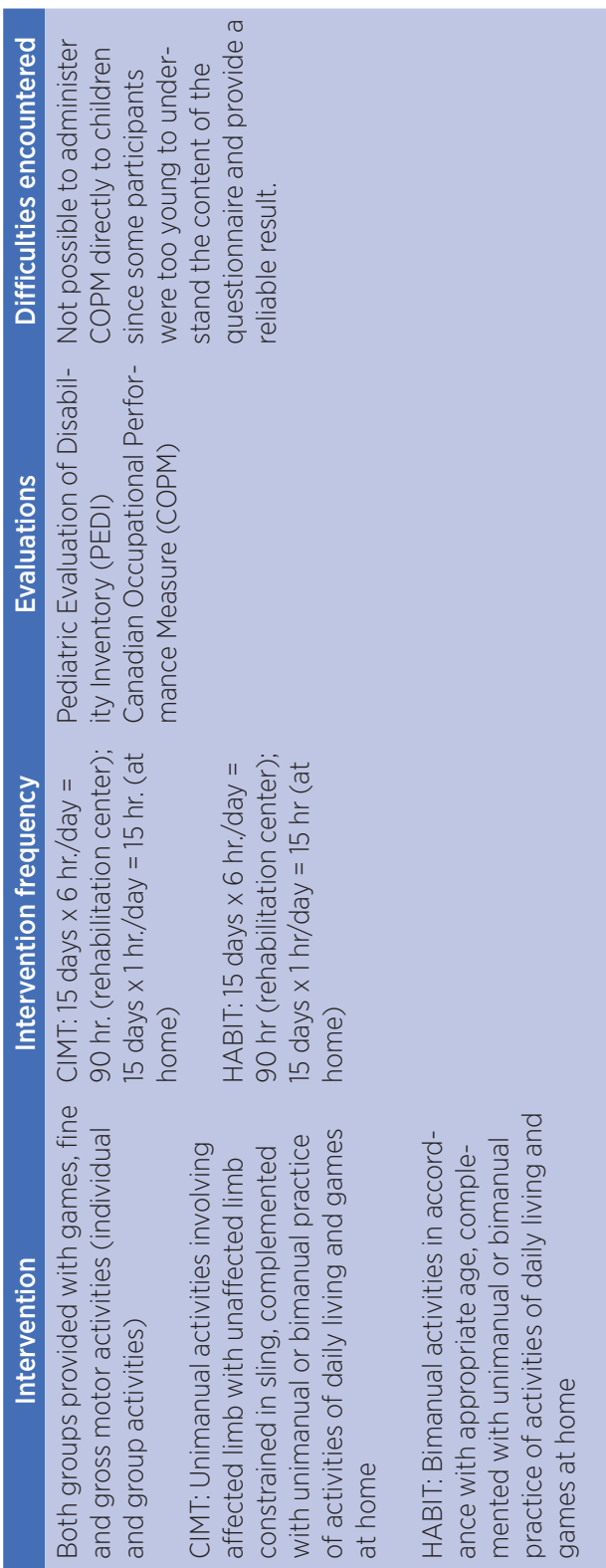

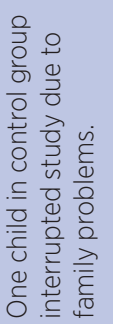

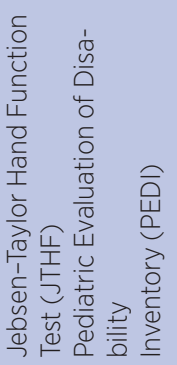

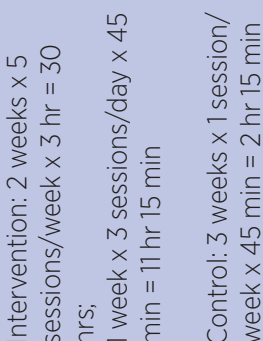

$\sim+\frac{1}{\pi}$

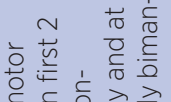

है.

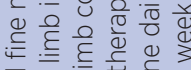

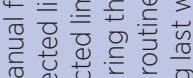

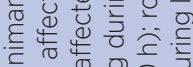

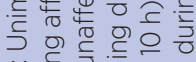

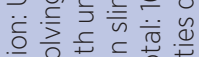

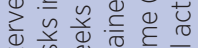

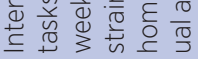

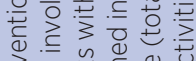

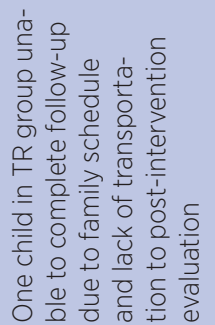



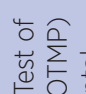

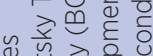

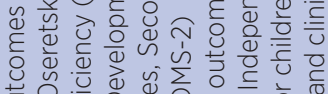

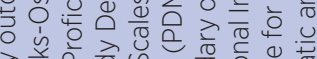

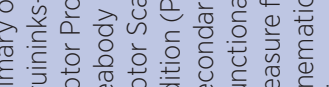

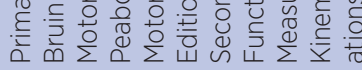

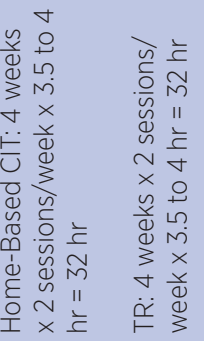

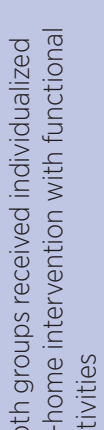

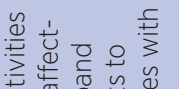

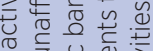

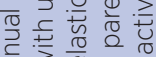

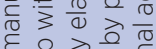 ह을응 है 음웜

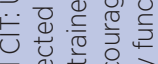 O

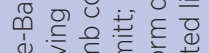

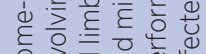

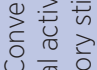

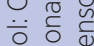

온 은

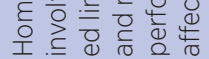

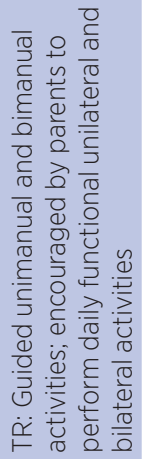

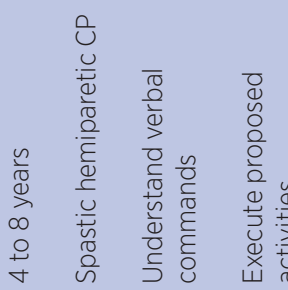

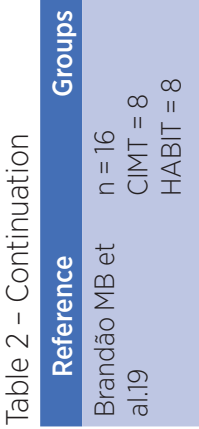

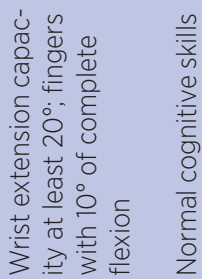
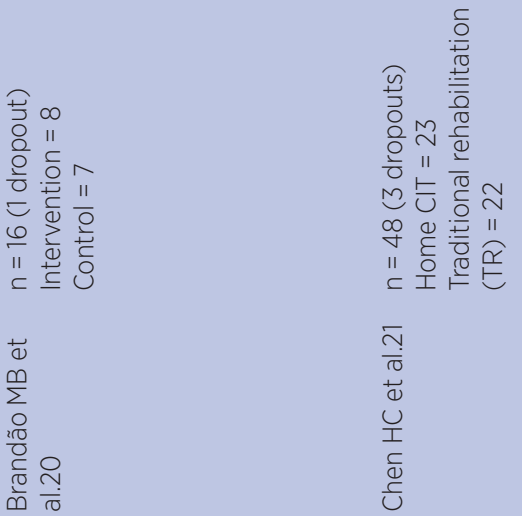


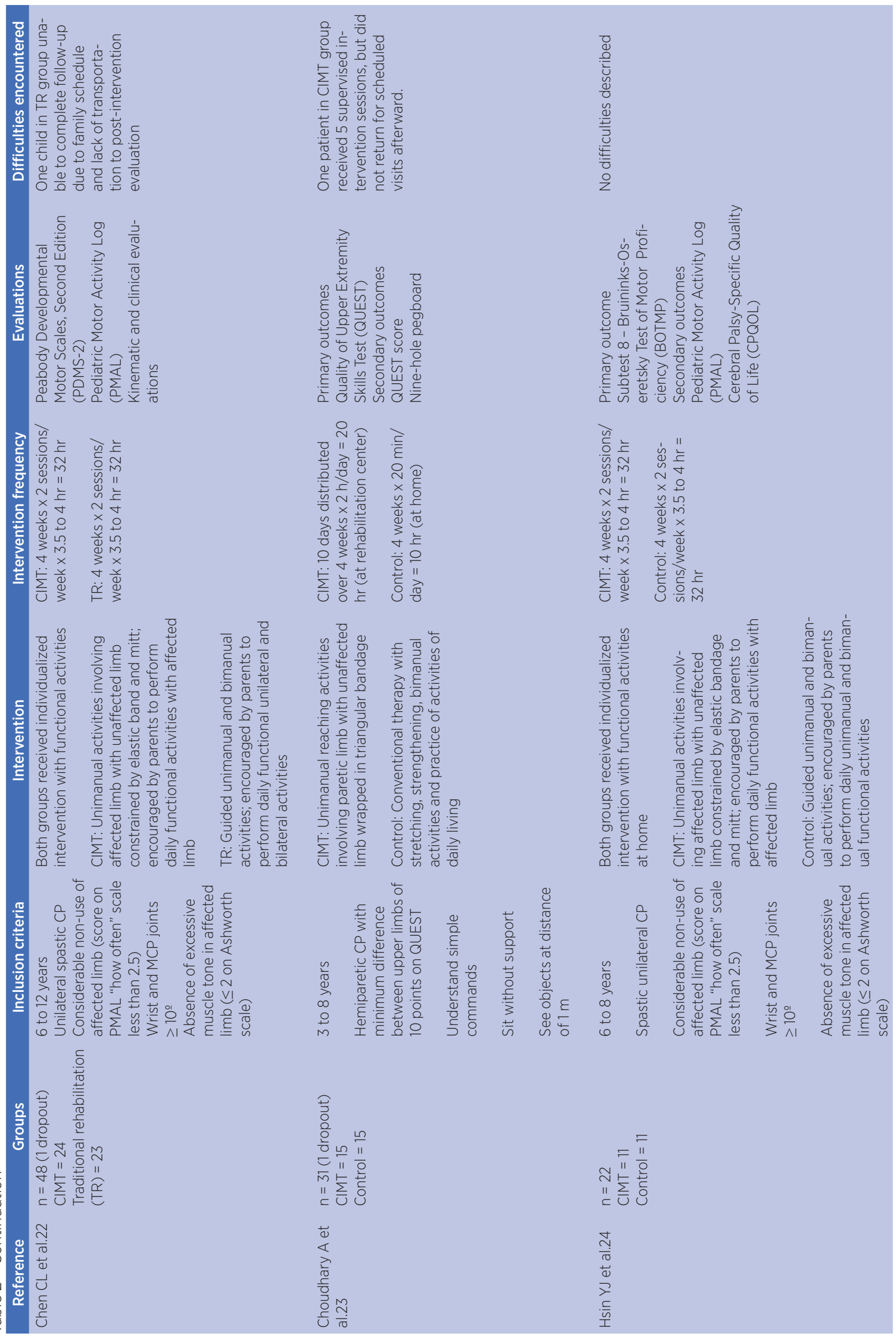




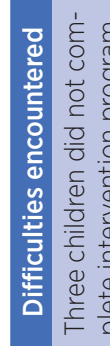

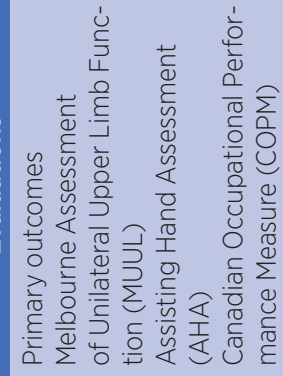

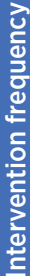

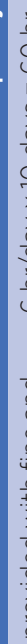

运证竞

흘

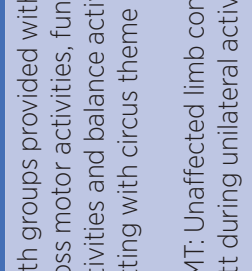

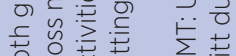

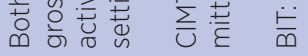
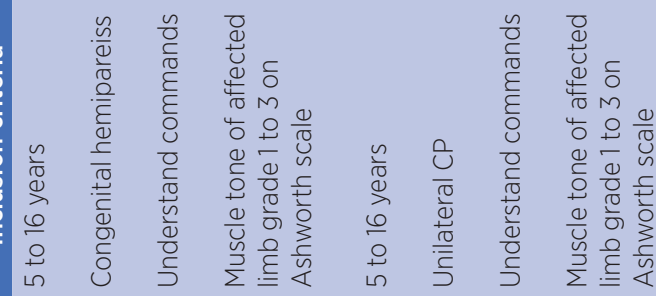

䒓这 $\frac{0}{11}$

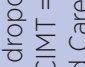

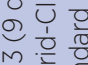

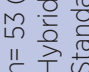

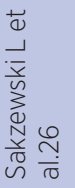

M $\bar{M} O$

过
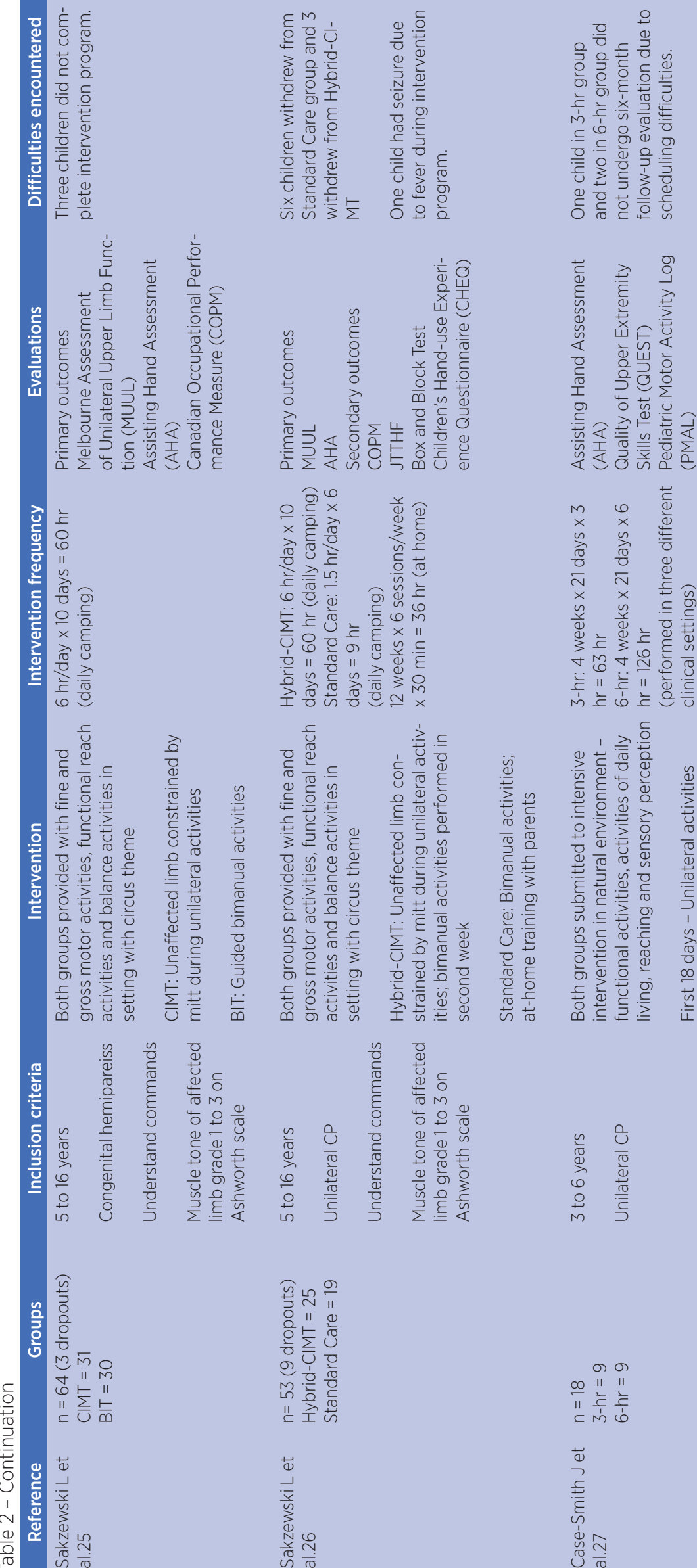
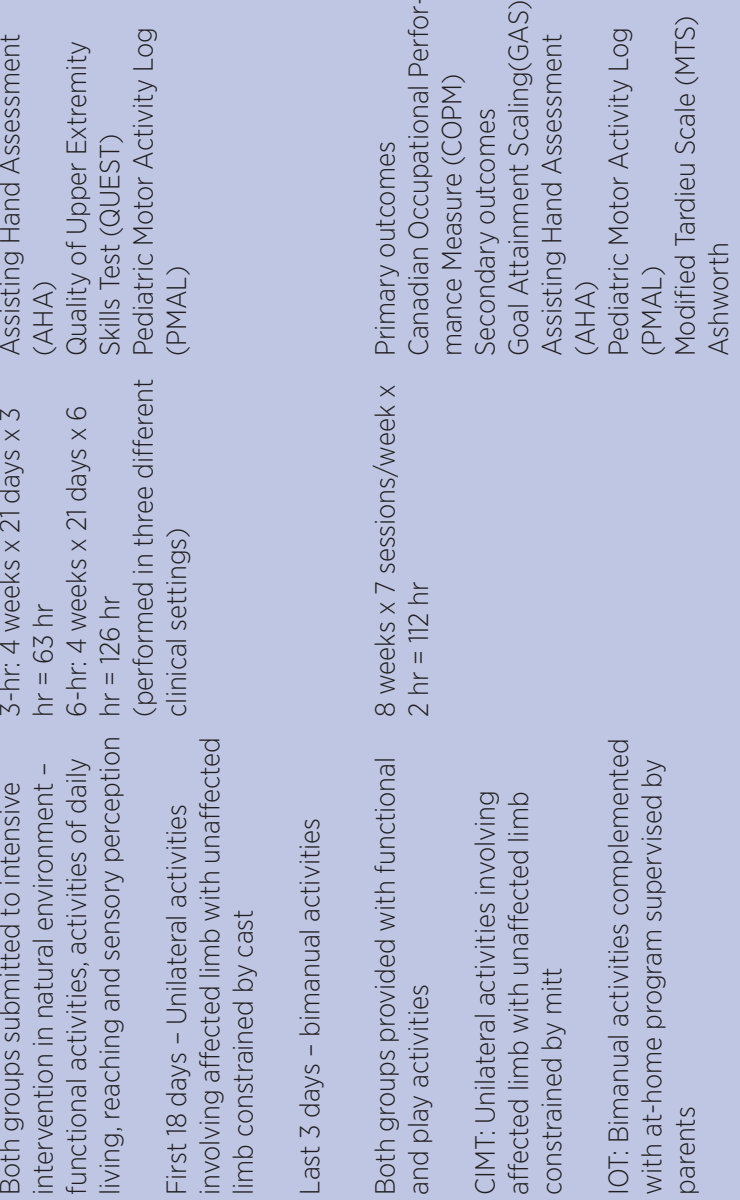

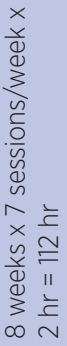
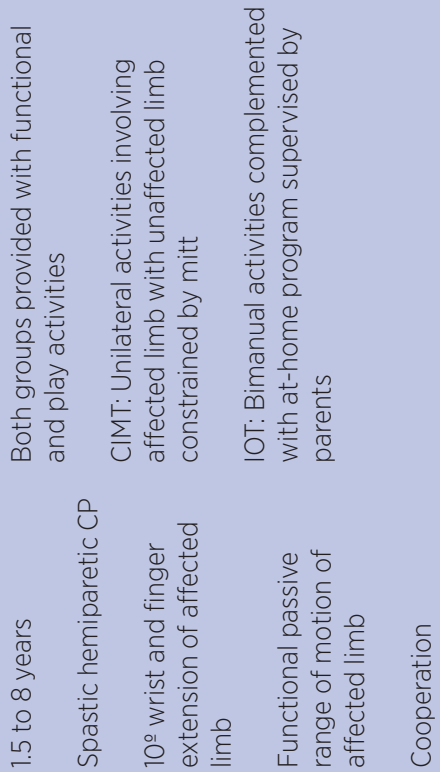

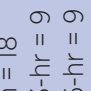<smiles>C1C2CC1C2</smiles>

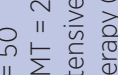
U元志

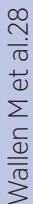


Table 3 - Outcomes of studies

\begin{tabular}{|c|c|}
\hline Reference & Outcomes \\
\hline Aarts PB et al. ${ }^{17}$ & $\begin{array}{l}\text { Improvements on AHA and ABILHAND-KIDS in both groups, with slight diminishment at follow-up; Improvements on Mel- } \\
\text { bourne, COPM and GAS in both groups, with increased improvement at follow-up }\end{array}$ \\
\hline Aarts PB et al. ${ }^{18}$ & $\begin{array}{l}\text { "Capacity" and "performance" scores on VOAA-DDD increased, whereas "development" score remained stable in CIMT-BT } \\
\text { group; No improvement in scores of Control group after intervention, but improvement in "performance" at follow-up; No } \\
\text { significant improvements in active or passive range of motion in either group }\end{array}$ \\
\hline $\begin{array}{l}\text { Brandão MB et al. }{ }^{19} \\
\text { Brandão MB et al. }{ }^{20}\end{array}$ & $\begin{array}{l}\text { Improvements in "self-care", "independence" (PEDI), "performance" and "satisfaction" (COPM) in both groups } \\
\text { No significant improvement on JTHF test in either group; Significant improvements in functional abilities and independence } \\
\text { (PEDI) in both groups at post-intervention and follow-up evaluations }\end{array}$ \\
\hline Chen $\mathrm{HC}$ et al. ${ }^{21}$ & $\begin{array}{l}\text { Improvements on "grasping" subscale (PDMS-2), subtest } 8 \text { (BOTMP), "self-care" subscale (WeeFIM), kinematic analyses of } \\
\text { reach and grasping in both groups at post-intervention and both follow-up ( } 3 \text { and } 6 \text { months) evaluations }\end{array}$ \\
\hline Chen $C L$ et al. ${ }^{22}$ & $\begin{array}{l}\text { CIMT group demonstrated significant improvement on "grasping" subscale (PDMS-2), quality/quantity of hand use (PMAL), } \\
\text { reaction time, normalized movement time and peak velocity in comparison to TR group. }\end{array}$ \\
\hline Choudhary A et al. ${ }^{23}$ & $\begin{array}{l}\text { CIMT group demonstrated significant improvement in QUEST score and time required to complete nine-hole pegboard test } \\
\text { in comparison to Control, with difference persisting at both follow-up evaluations ( } 4 \text { and } 8 \text { weeks). }\end{array}$ \\
\hline Hsin YJ et al. ${ }^{24}$ & $\begin{array}{l}\text { Improvements on BOTMP subtest } 8 \text { in both groups at post-intervention and 3-month follow-up evaluations; Improvement on } \\
\text { PMAL in both groups, with CIMT group demonstrating greater quality/quantity of hand use than Contro/ group, persisting at } \\
\text { 3-month follow up }\end{array}$ \\
\hline Sakzewski L et al. ${ }^{25}$ & $\begin{array}{l}\text { Older children, those with left-side hemiparesis and those with poorer manual function benefitted more from therapy. Better } \\
\text { effect on MUUL in CIMT group than BIT group; More changes in AHA in BIT group than CIMT group }\end{array}$ \\
\hline Sakzewski L et al. ${ }^{26}$ & $\begin{array}{l}\text { Significant improvements in "satisfaction", "performance" (COPM) and dexterity (BBT and JTTHF) in both groups; Significant } \\
\text { gains in AHA in Standard Care group at } 26 \text {-week follow-up evaluation }\end{array}$ \\
\hline Case-Smith J et al. ${ }^{27}$ & Significant improvements in AHA, PMAL and movement dissociation (QUEST) in both groups \\
\hline Wallen $\mathrm{M}$ et al. ${ }^{28}$ & Significant improvements in post-intervention "satisfaction" and "performance" (COPM) in both groups \\
\hline
\end{tabular}

\section{DISCUSSION}

Classic CIMT was originally developed for adults with neurological disorders and consequent motor impairment, and involves the constraint of the unaffected upper limb with a sling, mitt or other type of device for $90 \%$ of the day for 14 consecutive days. The patient engages in six hours of intensive training of the affected upper limb for 10 of the 14 days using a set of activities involving repetitive actions and formation therapy. Morris et al. ${ }^{29}$ highlight the importance of constraining the unaffected limb for $90 \%$ of the time during the intervention for the reorganization of the motor cortex and the long-term increase in the use of the affected limb. A substantial number of studies published in recent years demonstrate that CIMT leads to considerable neuroplastic cortical reorganization and to improved function of the upper limb in both the short and long terms. In a pioneering study, Liepert et al. ${ }^{30}$ employed transcranial magnetic stimulation to demonstrate an increase in the area of cortical representation of the affected limb following CIMT as well as improved limb use, as demonstrated by the Motor Activity Log.

In all studies analyzed in the present systematic review, games and functional activities were used during CIMT, but methodological quality, sample size, treatment modality, training intensity and evaluation tools differed among the studies. CIMT was not employed in its classic form and was modified with respect to the constraint method, duration of constraint (days or weeks), type and duration of therapy, intervention setting (home, school or clinic) and intervention provider (therapist, parent or teacher). The first significant variant was the method employed to constrain the unaffected limb, for which a range of techniques was used, such as a mitt ${ }^{21,22,24-26,28}$, sling ${ }^{17-20}$, cast $^{27}$ and splint ${ }^{23}$. Secondly, the treatment programs varied the intensity, ranging from 4 weeks of intervention distributed in 10 days, 2 hours a day, totaling 20 hours of intervention ${ }^{23}$ for 4 weeks, distributed in 21 days, 6 hours per session, totaling 126 hours of intervention ${ }^{27}$. The fact that the frequency, intensity and duration varied among the trials analyzed in the present review limits the development of guidelines regarding these aspects in interventions involving CIMT for children with CP.

In two clinical trials conducted by Aarts et al. ${ }^{17,18}$, the treatment group submitted to CIMT received more sessions per week and more hours per session than the control group, but the individuals in the control group complemented their training at home to match the total number of hours to which the treatment group was submitted. Choudhary et al..$^{23}$ conducted interventions on ten days distributed over a four-week period, in which the treatment group received two hours per day at a rehabilitation center, and the control group 
received 20 minutes a day at home. The clinical trials of Sakzewski L et al. ${ }^{25}$ also diverged in intensity in both groups (treatment and control).

The use of containment at home after treatment sessions was not used in any clinical trial. In some studies, children were encouraged to use the affected limb in functional and avd's activities at home under parental supervision, with no need for restraint of the affected $\operatorname{limb}^{21,22,24}$ or were submitted to complementary therapy with unimanual and bimanual exercises through games at home ${ }^{19}$. Chen et al. ${ }^{21}$ employed home-based CIMT, which consisted of the same principles as modified CIMT, but the therapist conducted the training in the child's home. A hybrid CIMT was used by Sakzewski et al. $^{26}$, which was composed of the combination of modified CIMT and bimanual training involving high intensity duration with the aim of improving unimanual and bimanual capacity.

All authors of the selected studies specified the children's age and degree of impairment at the time of treatment, which were chosen based on the expected benefits of treatment. For the functional classification of individuals eligible for inclusion in the study, the Manual Abilities Classification System (MACS) was used in two studies ${ }^{17,18}$, which was developed to categorize, respectively, the mobility and manual function of children with $\mathrm{CP}^{31,32}$. Other studies included in this review used the results of the Quality of Upper Extremity Skills Test (QUEST), Pediatric Motor Activity Log (PMAL) and Jebsen-Taylor Hand Function Test (JTHF) as part of the inclusion criteria ${ }^{19,22-24}$. It is recognized that the PMAL evaluation scale is an evaluation tool of little reliability and insufficient validity ${ }^{33}$. Minimum functional capacities of the affected limb were also used in the majority of studies, which required minimum wrist extension and finger flexion of $10^{\circ}$. The classification of muscle tone at the time of treatment was determined in some studies, using grades 1 and 2 of the modified Ashworth Scale as part of the inclusion criteria. Cognitive capacity, cooperation and comprehension of the commands were employed as inclusion criteria in the majority of studies, which are essential to conducting studies of this nature and obtaining the expected benefits. According to Moura ${ }^{34}$, adequate treatment planning is fundamental and requires ample knowledge of all upper limb disorders. A clinical evaluation combined with quantitative upper limb measures can provide necessary information for the detection of clinically significant changes in upper limb function, following an intervention.

All studies selected presented valid and reliable results using one or more types of primary and secondary evaluations. The PMAL, QUEST, Canadian Occupational Performance Measure (COPM) and Assisting Hand Assessment (AHA) were the most used outcome measures. In two clinical trials, Aarts et al. ${ }^{17,18}$ used the COPM, AHA, ABILHAND-KIDS, Melbourne Assessment of Unilateral Upper Limb Function (MUUL) and Goal Attainment Scaling (GAS) as well as the Determine Developmental Disregard module of the Video Observations Aarts and Aarts module (VOAADDD), which was created by the authors themselves. The Bruininks-Oseretsky Test of Motor Proficiency (BOTMP) was used in two studies ${ }^{21,24}$, the Peabody Developmental Motor Scales - Second Edition (PDMS-2) was used in two studies ${ }^{21,22}$ and the Pediatric Evaluation of Disability Inventory (PEDI) was used by Brandão et al. ${ }^{19}$.

Other outcome measures were employed in the remaining studies. The Functional Independence Measure for Children (WeeFIM), together with a kinematic evaluation, was used in the study by Chen et $a .^{21}$ for the evaluation of performance on activities of daily living and functional independence. Hsin et al. ${ }^{24}$ employed the Cerebral Palsy-Specific Quality of Life (CPQOL) assessment tool as a secondary outcome measure ${ }^{35}$. Along with other measures, Sakzewski et al. ${ }^{26}$ used the Box and Block Test and Children's Hand-Use Experience Questionnaire (CHEQ) as secondary outcome measures. Along with previously described measures, Wallen et al. ${ }^{28}$ used the Modified Tardieu Scale (MTS) and Modified Ashworth Scale as secondary outcome measures for the evaluation of spasticity of the elbow flexors as well as the wrist pronators and extenders.

All studies included in the present systematic review reported significant improvements in some outcome measure, demonstrating the positive effects of the proposed treatment during both the post-intervention and follow-up evaluations. Despite the small sample sizes, all studies offered satisfactory consistency regarding the outcome measures.

The majority of studies reported difficulties with the use of CIMT for children with $\mathrm{CP}$, but the reason for the found difficulties does not have the correlation of something with a restraint of a non-affected limb 
or there is a process of irritability during a therapy. In 9 of the 12 clinical trials ${ }^{17-20,22,23,25-27}$, difficulties and dropouts occurred due to family problems, scheduling problems, changes of address and a lack of transportation. In the study by Sakzewski et al. ${ }^{26}$, nine of the participants dropped out of the study groups and a seizure occurred in one child during treatment; however, the authors did not describe the dropouts in detail. In the study by Chen et al. ${ }^{21}$, dropouts occurred due to family problems and two children were excluded from the study during treatment due to a lack of sufficient motor skills to perform the kinematic evaluation of the reaching task proposed as an outcome measure. Brandão et al. ${ }^{19}$ found that it was impossible to administer the COPM directly to the children due to their young age and difficulty of understanding the questionnaire content, which was therefore answered by parents/caregivers.

Based on the studies selected for the present review, CIMT requires modifications for children with $\mathrm{CP}$ and the children's response to a given intervention needs to be evaluated using a biopsychosocial approach, which can directly or indirectly exert an influence on the results. Information regarding the types of intervention, modifications and doseresponse relationship as well as the effects on structural and functional changes in children with $\mathrm{CP}$ is fundamental to the development of guidelines for the reliable, reproducible practice of CIMT.

\section{CONCLUSION}

The present systematic review of the literature findings demonstrate that, despite the lack of a common methodology among studies regarding the use of constraint-induced movement therapy for children with cerebral palsy, this form of intervention has been adapted with considerable flexibility, providing promising, positive results of the therapeutic intervention of the paretic upper limb.

This systematic review is not intended to synthesize and evaluate the results obtained with the use of the CIMT in clinical trials, but only to demonstrate its use and/or possible modifications/adaptations in clinical practice. Because of this limitation in our study, a summary of outcome measures is required, as well as synthesis of data on the studies reviewed in a future version.

\section{DISCLOSURE}

The authors declare no conflicts of interest in relation to this study. The authors alone are responsible for the content and writing of the paper. No commercial party having a direct financial interest in the results of the research supporting this article has or will confer a benefit upon the authors or upon any organization with which the authors are associated. This systematic review was conducted in compliance with the norms of the Preferred Reporting Items for Systematic Reviews and Meta-Analyses (PRISMA).

\section{REFERENCES}

1. Gordon AM, Charles J, Wolf SL. Methods of constraintinduced movement therapy for children with hemiplegic cerebral palsy: development of a child-friendly intervention for improving upper-extremity function. Arch Phys Med Rehabil. 2005;86(4):837-44. doi: 10.1016/j.apmr.2004.10.008

2. Andersen JC, Majnemer A, O'Grady K, Gordon AM. Intensive upper extremity training for children with hemiplegia: from science to practice. Semin Pediatr Neurol. 2013;20(2):100-5. doi: 10.1016/j.spen.2013.06.001

3. Balleoti LR, Gritti CC, Silva BC. Efeitos de um protocolo modificado da terapia por contensão induzida em criança com paralisia cerebral hemiparética. Rev Ter Ocup Univ São Paulo. 2014;25(3):264-71. http://dx.doi.org/10.11606/ issn.2238-6149.v25i3p264-271

4. Sakzewski L, Ziviani J, Boyd RN. Efficacy of upper limb therapies for unilateral cerebral palsy: a metaanalysis. Pediatrics. 2014;133(1):175-204. doi: 10.1542/ peds.2013-0675

5. Silva LA, Tamashiro V, Assis RD. Terapia por contenção induzida: revisão de ensaios clínicos. Fisioter Mov. 2010;23(1):153-59. doi: 10.1590/S0103-51502010000100015

6. Diniz L, Abranches MHS. Neuroplasticidade na terapia de restrição e indução do movimento em pacientes com acidente vascular encefálico. Med Reabil. 2003;22(3):53-5.

7. Liepert J, Bauder H, Miltner WHR, Taub E, Weiller C. Treamentinduced cortical reorganization after stroke in humans. Stroke. 2000;31(6):1210-6. doi: 10.1161/01.STR.31.6.1210

8. Bleyenheuft Y, Arnould C, Brandão MB, Bleyenheunft C, Gordon AM. Hand and arm bimanual intensive therapy including lower extremity (HABIT-ILE) in children with unilateral spastic cerebral palsy: a randomized trial. Neurorehabil Neural Repair. 2015;29(7):645-57. doi: 10.1177/1545968314562109

9. Taub E, Miller NE, Novack TA, Cook EW, Fleming WC, Neponucemo CS, et al. Technique to improve chronic motor deficit after stroke. Arch Phys Med Rehabil. 1993;74(4):347-54.

10. Taub E, Uswatte G, Pidikiti R. Constraint-induced movement therapy: a new family of techniques with broad application to physical rehabilitation: a clinical review. J Rehabil Res Dev. 1999;36(3):237-51. 
11. Eliasson AC, Krumlinde-Sundholm L, Gordon AM, Feys $H$, Klingels K, Aarts, PBM, et al. Guidelines for future research in constraint-induced movement therapy for children with unilateral cerebral palsy: an expert consensus. Dev Med Child Neurol. 2014;56(2):125-37. doi: 10.1111/dmcn.12273

12. Taub E. The behavior-analytic origins of constraintinduced movement therapy: an example of behavioral neurorehabilitation. Behav Anal. 2012;35(2):155-78.

13. DeLuca SC, Echols K, Law CR, Ramey SL. Intensive pediatric constraint-induced therapy for children with cerebral palsy: randomized, controlled, crossover trial. J Child Neurol. 2006;21(11):931-8. doi 10.2310/7010.2006.00201

14. Dong VA, Tung $\mathrm{H}$, Siu HW, Fong KN. Studies comparing the efficacy of constraint-induced movement therapy and bimanual training in children with unilateral cerebral palsy: a systematic review. Dev Neurorehabil. 2013;16(2):133-43. doi: 10.3109/17518423.2012.702136

15. Chen YP, Pope S, Tyler D, Warren GL. Effectiveness of constraint-induced movement therapy on upperextremity function in children with cerebral palsy: a systematic review and meta-analysis of randomized controlled trials. Clin Rehabil. 2014;28(10):939-53. doi: 10.1177/0269215514544982

16. Shiwa SR, Costa LOP, Moser ADL, Aguiar IC, Oliveira LVF. PEDro: the physiopherapy evidence database. Fisioter Mov. 2011;24(3):523-33. doi: 10.1590/S0103-51502011000300017

17. Aarts PB, Jongerious PH, Geerdink YA, van Limbeek J, Geurts AC. Effectiveness of modified constraint-induced movement therapy in children with unilateral spastic cerebral palsy: a randomized controlled trial. Neurorehabil Neural Repair. 2010;24(6):509-18. doi: 10.1177/1545968309359767

18. Aarts PB, Jongerious PH, Geerdink YA, van Limbeek J, Geurts AC. Modified constraint-induced movement therapy combined with bimanual training (mCIMT-BiT) in children with unilateral spastic cerebral palsy: how are improvements in arm-hand use established? Res Dev Disabil. 2011;32(1):2719. doi: 10.1016/j.ridd.2010.10.008

19. Brandão MB; Gordon AM; Mancini MC. Functional impact of constraint therapy and bimanual training in children with cerebral palsy: a randomized controlled trial. Am J Occup Ther. 2012;66(6):672-81. doi:10.5014/ajot.2012.004622

20. Brandão MB, Mancini MC, Vaz DV, Fonseca ST. Adapted version of constraint-induced movement therapy promotes functioning in children with cerebral palsy: a randomized controlled trial. Clin Rehabil. 2010;24(7):639-47. doi: 10.1177/0269215510367974

21. Chen HC, Chen CL, Kang LJ, Wu CY, Chen FC, Hong WH. Improvement of upper extremity motor control and function after home-based constraint induced therapy in children with unilateral cerebral palsy: immediate and long-term effects. Arch Phys Med Rehabil. 2014;95(8):1423-32. doi: 10.1016/j. apmr.2014.03.025

22. Chen CL, Kang LJ, Hong WH, Chen FC, Chen HC, Wu CY. Effect of therapist-based constraint-induced therapy at home on motor control, motor performance and daily function in children with cerebral palsy: a randomized controlled study. Clin Rehabil. 2013;27(3):236-45. doi: $10.1177 / 0269215512455652$
23. Choudhary A, Gulati S, Kabra, M, Singh UP, Sankhyan N, Pandey RM, et al. Efficacy of modified constraint induce movement therapy in improving upper limb function in children with hemiplegic cerebral palsy: a randomized controlled trial. Brain Dev. 2013;35(9):870-6. doi: 10.1016/j.braindev.2012.11.001

24. Hsin YJ, Chen FC, Lin KC, Kang LJ, Chen CL, Chen CY. Efficacy of constraint-induced therapy on functional performance and health-related quality of life for children with cerebral palsy: a randomized controlled trial. J Child Neurol. 2012; 27(8):992-9. doi: 10.1177/0883073811431011

25. Sakzewski L, Ziviani J, Boyd RN. Best responders after intensive upper-limb training for children with unilateral cerebral palsy. Arch Phys Med Rehabil. 2011;92(4):578-84. doi: 10.1016/j.apmr.2010.12.003

26. Sakzewski L, Miller L, Ziviani J, Abbott D, Rose S, Macdonell RA, et al. Randomized comparison trial of density and context of upper limb intensive group versus individualized occupational therapy for children with unilateral cerebral palsy. Dev Med Child Neurol. 2015;57(6):539-47. doi: 10.1111/ dmcn.12702

27. Case-Smith J, DeLuca SC, Stevenson R, Ramey SL. Multicenter randomized controlled trial of pediatric constraint-induced movement therapy: 6-month follow-up. Am J Occup Ther. 2012;66(1):15-23. doi:10.5014/ajot.2012.002386

28. Wallen M, Ziviani J, Naylor N, Evans R, Novak I, Herbert RD. Modified constraint-induced therapy for children with hemiplegic cerebral palsy: a randomized trial. Dev Med Child Neurol.2011;53(12):1091-9.doi:10.1111/j.1469-8749.2011.04086.x

29. Morris DM, Taub E, Mark VW. Constraint-induced movement therapy: characterizing the intervention protocol. Eura Medicophys. 2006;42(3):257-68.

30. Liepert J, Bauder H, Miltner WHR, Taub E, Weiller C. Treatmentinduced cortical reorganization after stroke in humans. Stroke. 2000;31(6):1210-6. doi: 10.1161/01.STR.31.6.1210

31. Eliasson AC, Krumlinde-Sundholm L, Shaw K, Wang C. Effects of constraint-induced movement therapy in young children with hemiplegic cerebral palsy: an adapted model. Dev Med Child Neurol. 2005;47(4):266-75.

32. Eliasson AC, Krumlinde-Sundholm L, Rösblad B, Beckung E, Arner M, Ohrvall AM, et al. The Manual Ability Classification System (MACS) for children with cerebral palsy: scale development and evidence of validity and reliability. Dev Med Child Neurol. 2006;48(7):549-54. doi: 10.1017/ S0012162206001162

33. Wallen, M, Ziviani, J. Caution regarding the pediatric motor activity log to measure upper limb intervention outcomes for children with unilateral cerebral palsy. Dev Med Child Neurol. 2013;55(6):497-8. doi: 10.1111/dmcn.12057

34. Moura RCF, Almeida CS, Dumont AJ, Lazzari RD, Lopes $J B$, Duarte NAC, et al. Kinematic upper limb evaluation of children and adolescents with cerebral palsy: a systematic review of the literature. J Phys Ther Sci. 2016;28(2):695-700. doi:10.1589/jpts.28.695

35. Waters E; Davis E; Mackinnon A, Boyd R, Graham HK, Kai Lo S, et al. Psychometric properties of the quality of life questionnaire for children with CP. Dev Med Child Neurol. 2007;49(1):49-55. doi: 10.1111/j.1469-8749.2007.0126a.x 